\title{
Optimization of the composition of austenitic stainless nitrogen- containing steels with high corrosion and mechanical properties
}

\author{
Vera Berezovskaya $^{1,{ }^{*},}$ Evgeny Merkushkin ${ }^{1}$, and Alexey Ananyin ${ }^{1}$ \\ ${ }^{1}$ UrFU, Institute of New Materials and Technologies, 620002, Mira st., 19, Ekaterinburg, Russia
}

\begin{abstract}
The study investigated 16 grades of austenitic stainless steels (ASS) with different chemical composition, including nitrogen. Metallographic and electrochemical studies of pitting corrosion in a solution of $3.5 \% \mathrm{NaCl}$ (GOST 9.912) were carried out. The optimum ratios of carbon and nitrogen concentrations in ASS are determined, which allow obtaining high resistance to pitting corrosion and high strength. Equation of the dependence of break down potential $E_{\mathrm{b}}$ and strength $\left(R_{\mathrm{p} 0.2}\right.$ and $\left.R_{\mathrm{m}}\right)$ on the chemical composition of the steels with nitrogen were proposed. The effect of heat treatment and severe plastic deformation on the pitting resistance, mechanical and paramagnetic properties of the HNS has been studied. It was shown that during SPD, the HNS strength increased by about 3 times, while the fracture was not brittle and occurred by the quasi-cleavage mechanism. Although the potential of $E_{\mathrm{b}}$ decreased, it remained higher than that of steel $09 \mathrm{Cr} 18 \mathrm{Ni} 10 \mathrm{Ti}$. The HNS of the investigated composition also showed high resistance to stress corrosion cracking in a quenched and aged at $500{ }^{\circ} \mathrm{C}$ states, and did not show embrittlement in a corrosive environment even after SPD.
\end{abstract}

\section{Introduction}

With the increase in the use of high-nitrogen austenitic steels (HNS), the effect of nitrogen on corrosion has been the subject of very intensive study. Both positive and negative effects of nitrogen on general corrosion are reported. Nevertheless, the positive effect of nitrogen on the resistance of local (pitting and crevice) corrosion can be clearly seen in most literary sources.

It has been shown [1] that in nitrogen-containing $\mathrm{Cr}$ $\mathrm{Ni}$ steels tested for pitting corrosion (PC) in $0.01 \mathrm{M}$ $\mathrm{FeCl}_{3}$, the maximum pitting depth decreases with increasing nitrogen content in a parabolic relationship. It is noted that with an increase in nitrogen content from 0.07 to $0.22 \%$, the value of one of the parameters of electrochemical noise - the charge factor, decreases. The increase in the resistance of nitrogen alloying (up to $0.6 \%$ ) Cr-Ni-Mo steel PC with an increase in nitrogen content is connected, according to the authors [2], to the fact that it: 1) increases the incubation period for the formation of secondary phases; 2) contributes to the precipitate of nitrides $\mathrm{Cr}_{2} \mathrm{~N}$ and delays the formation of carbides $\mathrm{M}_{23} \mathrm{C}_{6}$; and 3) reduces the growth rate of pits, increasing the ability of the steel to passivation.

It was also found [3] that a very high nitrogen content may adversely affect austenitic corrosionresistant steels (ASS), subjected to cold working. With a high nitrogen content, the cellular dislocation structure is crushed, which is accompanied by an increase in the density of dislocations. This creates the conditions for the birth of pitting. In addition, the shear of ordered Cr-N clusters and the formation of chromium-enriched clusters together with a depleted chromium $\gamma$-solid solution around them leads to the formation of microgalvanic elements that enhance corrosion. In addition, the ambiguous effect of cold plastic deformation (CPD) on the resistance of $\mathrm{PC} \mathrm{Cr}-\mathrm{Ni}-\mathrm{Mo}$ steels with different nitrogen content is shown. The resistance of $\mathrm{PC}$ in a neutral chloride medium increases with the degree of CPD to $20 \%$, whereas with degrees of 30 and $40 \%$ it decreases significantly. In steel with a high nitrogen content, this is manifested in a decrease in size and an increase in the density of pits along the slip bands at high degrees of deformation.

It was established [4] that in a $3.5 \% \mathrm{NaCl}$ solution with increasing degree of $\mathrm{CPD}$, the break down potential $\mathrm{E}_{\mathrm{b}}$ (potential pitting formation) of nickel-free $\mathrm{Cr}-\mathrm{Mn}-\mathrm{Mo}$ steel $(0.66 \% \mathrm{~N})$ decreases due to the formation of a looser and less resistant passive film due to the high density of defects in steel.

As you know, the HNS problem is the formation of chromium nitrides in the process of aging at temperatures of $500-1050^{\circ} \mathrm{C}$. This leads to a significant reduction in corrosion resistance due to the depletion of chromium on the border to the nitrides $\mathrm{Cr}_{2} \mathrm{~N}$ zones. As a result of studies [5], it was determined that in Cr-Mn-Mo steel with $0.87 \%$ (A) of nitrogen, $\mathrm{Cr}_{2} \mathrm{~N}$ nitrides were formed during aging along the grain boundaries. In steel with a higher nitrogen content of $1.07 \%(\mathrm{~B})$, nitrides were initially precipitated along the grain boundaries, and with further aging in the form of a lamella structure. Steel B had a higher resistance to PC as long as the nitrides stood out along the grain boundaries; however, as soon as their formation began in the form of lamellae,

* Corresponding author: ber6141@yandex.ru 
steel B became more susceptible to PC than steel A. It was also revealed that $\mathrm{Cr}_{2} \mathrm{~N}$ lamella nitrides are the most PC-susceptibility areas compared to other inhomogeneities, such as (Mn,Cr)-oxides or $\mathrm{Cr}_{2} \mathrm{~N}$ nitrides, precipitated at grain boundaries.

The PC of austenitic Cr-Ni-Mo steel with nitrogen $(0.1-0.16 \% \mathrm{~N})$ was studied in comparison with $\mathrm{Cr}-\mathrm{Ni}-\mathrm{Ti}$ steel without nitrogen [6]. The samples were annealed at various temperatures, followed by cooling in water. As the annealing temperature increases in the range of $1000-1150^{\circ} \mathrm{C}$, the potential $E_{\mathrm{b}}$ of steels after quenching increased, respectively, to 519 and $302 \mathrm{mV}$, for steels with and without nitrogen, and when quenched from higher annealing temperatures, $\mathrm{E}_{\mathrm{b}}$ decreased. In addition to the higher potential $E_{b}$, the steel with nitrogen showed a more stable passive region on the anodic polarization curves.

\section{Materials and methods}

Investigated ASS industrial melts, as well as Cr-MnHNS, melted by the method of smelting under the slag with nitrogen-containing additives $\left(\mathrm{Si}_{3} \mathrm{~N}_{4}\right)$ and high $(2.5$ $\mathrm{MPa}$ ) nitrogen pressure. The chemical composition of the investigated steels is shown in Table. 1.

Properties of HNS were studied on the steel 06Ch18AG19M2 in different structural states formed as a result of thermal and combined treatments. The scheme of different treatment modes is shown in Fig. 1.

By electrochemical method according to GOST 9.912-89 using the VoltaLab 10-PGZ100 electrochemical laboratory and software VoltaMaster 4 were investigated the pitting corrosion of the steels. The reference electrode was a saturated silver/silver chloride electrode (SSCE), the auxiliary electrode was a platinum electrode. The tests were carried out at room temperature in a $3.5 \%$ aqueous solution of sodium chloride.

The obtained results were compared with the calculated values of the indicator PREN, which depended on the content of elements in steel (in wt.\%) and was calculated from the equation given in [7]:

$$
\mathrm{PREN}=\mathrm{Cr}+3.3 \mathrm{Mo}+16 \mathrm{~N}
$$

Tensile properties of the steels were determined by the standard method (GOST 1497-84) on plate samples with a size of $100 \times 10 \times 1 \mathrm{~mm}$ on a TINIUS OLSEN H50KS machine with HORIZON software.

Fractographic and micro X-ray spectral analysis of the sample surface was performed on a TESCAN scanning electron microscope using a vacuum chamber and an Inca Energy 450 energy dispersive microanalysis system.

\section{Results and discussion}

\subsection{Austenitic stainless steels}

\subsubsection{Pitting corrosion}

PC parameters are given in Table. 2, from which it is clear that higher pitting resistance (high values of $E_{b}$ ) have ASS with a low content of manganese and a high content of nickel (steel nos. 1, 2, 9, 10). Steel 06H15AG9NM2 (No. 5) with 9\% manganese and a high nitrogen content $(0.166 \%)$ showed fairly high values of $\mathrm{PREN}=23.7$, although the low pitting potential is $\mathrm{E}_{\mathrm{b}}=$ $0.053 \mathrm{~V}$.

The effect of the main alloying elements on the pitting potential $\mathrm{E}_{\mathrm{b}}$ of steels is also considered (Fig. 2).

Table 1. Chemical composition of the investigated ASS and HNS.

\begin{tabular}{|c|c|c|c|c|c|c|c|c|c|c|c|c|c|c|}
\hline \multirow{2}{*}{ No. } & \multirow{2}{*}{ Steel grade } & \multicolumn{13}{|c|}{ Alloying elements, wt.\% } \\
\hline & & $\mathrm{C}$ & $\mathrm{S}$ & $\mathrm{P}$ & $\mathrm{Mn}$ & $\mathrm{Si}$ & $\mathrm{Cr}$ & $\mathrm{Ni}$ & Mo & $\mathrm{N}$ & $\mathrm{Cu}$ & $\mathrm{Ti}$ & $\mathrm{V}$ & $\mathrm{Al}$ \\
\hline 1 & 02Cr16Ni10MnMo2 & 0.02 & 0.001 & 0.017 & 1.38 & 0.51 & 16.12 & 10.17 & 2.04 & 0.037 & - & - & - & - \\
\hline 2 & $04 \mathrm{Cr} 18 \mathrm{Ni} 8 \mathrm{MnCu}$ & 0.04 & 0.003 & 0.024 & 1.42 & 0.39 & 18.30 & 8.15 & - & 0.043 & 0.10 & - & - & - \\
\hline 3 & 05Cr16Ni4Mn6Cu2 & 0.05 & 0.002 & 0.025 & 6.15 & 0.35 & 16.15 & 4.10 & - & 0.085 & 1.65 & - & - & - \\
\hline 4 & $08 \mathrm{Cr} 15 \mathrm{Mn} 10 \mathrm{Cu} 2$ & 0.08 & 0.002 & 0.030 & 9.78 & 0.32 & 14.50 & 0.16 & - & 0.163 & 1.62 & - & - & - \\
\hline 5 & 06Cr15Mn9NiMo2 & 0.06 & 0.003 & 0.025 & 9.20 & 0.32 & 14.80 & 0.95 & 1.68 & 0.166 & - & - & - & - \\
\hline 6 & $03 \mathrm{Cr} 17 \mathrm{Mn} 7 \mathrm{Ni} 4$ & 0.03 & 0.002 & 0.029 & 7.21 & 0.38 & 16.90 & 4.19 & 0.09 & 0.162 & 0.03 & - & - & - \\
\hline 7 & 09Cr15Mn9NiCu2 & 0.09 & 0.005 & 0.060 & 8.98 & 0.34 & 15.35 & 1.16 & 0.10 & 0.133 & 1.66 & - & - & - \\
\hline 8 & 09Cr16Mn9Ni2Cu2 & 0.09 & 0.002 & 0.052 & 8.61 & 0.23 & 16.13 & 1.73 & 0.06 & 0.169 & 2.15 & - & - & - \\
\hline 9 & 02Cr16Ni10MnMo2Cu & 0.02 & 0.008 & 0.032 & 1.18 & 0.30 & 16.48 & 10.10 & 2.04 & 0.035 & 0.38 & - & - & - \\
\hline 10 & 06Cr18Ni8MnCu & 0.06 & 0.006 & 0.038 & 0.84 & 0.34 & 18.04 & 8.04 & 0.19 & 0.035 & 0.28 & - & - & - \\
\hline 11 & 07Cr16Mn8Ni4Cu2 & 0.07 & 0.005 & 0.055 & 7.54 & 0.32 & 16.10 & 4.07 & 0.18 & 0.085 & 1.78 & - & - & - \\
\hline 12 & $01 \mathrm{Cr} 14 \mathrm{Mn} 10 \mathrm{Cu} 2$ & 0.21 & 0.012 & 0.090 & 10.19 & 0.42 & 13.85 & 0.23 & 0.01 & 0.150 & 1.93 & - & - & - \\
\hline 13 & 07Cr16Mn13Mo3 & 0.07 & 0.007 & 0.015 & 12.76 & 0.71 & 16.16 & 0.11 & 3.24 & 0.820 & - & - & 0.05 & - \\
\hline 14 & 06Cr18Mn19Mo2 & 0.06 & 0.001 & 0.018 & 19.13 & 0.65 & 17.51 & 0.13 & 2.20 & 0.810 & 0.03 & 0.002 & $0.08 \mathrm{~V}$ & 0.008 \\
\hline 15 & 03Cr20Mn11 Ni7Mo2 & 0.03 & 0.004 & 0.015 & 10.60 & 0.50 & 19.62 & 6.81 & 1.67 & 0.422 & - & - & $\begin{array}{c}0.22 \mathrm{~V} \\
0.18 \mathrm{Nb}\end{array}$ & - \\
\hline 16 & 09Cr18Ni10Ti & 0.07 & 0.016 & 0.015 & 0.22 & 0.59 & 17.66 & 9.18 & 0.15 & - & 0.28 & 0.543 & 0.054 & 0.128 \\
\hline
\end{tabular}




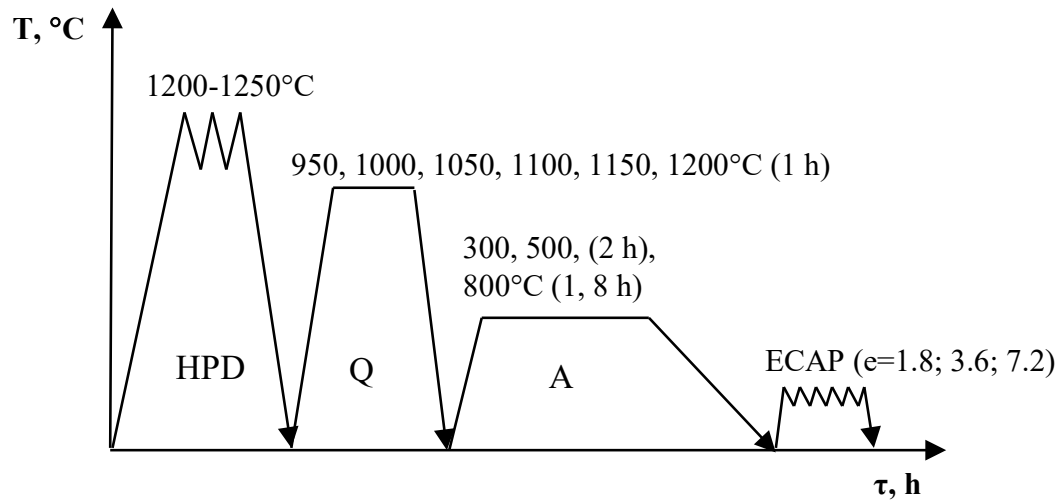

Fig. 1. Modes of steel processing: HPD - hot plastic deformation; Q - HPD + quenching in water; A - Q + aging; ECAP - equal channel angular pressing.

Table 2. Pitting resistance and mechanical tensile properties of ASS and HNS.

\begin{tabular}{|c|c|c|c|c|c|c|c|c|c|}
\hline \multirow{3}{*}{ No. } & \multirow{3}{*}{ Steel grade } & \multirow{3}{*}{ PREN } & \multirow{3}{*}{$E_{\mathrm{b}}[\mathrm{V}]$} & \multicolumn{3}{|c|}{ Air } & \multicolumn{3}{|c|}{$3.5 \%-\mathrm{NaCl}$} \\
\hline & & & & $R_{\mathrm{m}}$ & $R_{\mathrm{p} 0.2}$ & $A$ & $R_{\mathrm{m}}$ & $R_{\mathrm{p} 0.2}$ & $A$ \\
\hline & & & & \multicolumn{2}{|c|}{$[\mathrm{MPa}]$} & {$[\%]$} & \multicolumn{2}{|c|}{$[\mathrm{MPa}]$} & {$[\%]$} \\
\hline 1 & 02Cr16Ni10MnMo2 & 23.4 & 0.288 & 640 & 310 & 29 & 640 & 280 & 34 \\
\hline 2 & 04Cr18Ni8MnCu & 19.0 & 0.213 & 770 & 300 & 38 & 700 & 250 & 27 \\
\hline 3 & 05Cr16Ni4Mn6Cu2 & 17.5 & 0.074 & 710 & 340 & 37 & 690 & 300 & 23 \\
\hline 4 & $08 \mathrm{Cr} 15 \mathrm{Mn} 10 \mathrm{Cu} 2$ & 17.1 & -0.016 & 1050 & 520 & 39 & 760 & 440 & 17 \\
\hline 5 & 06Cr15Mn9NiMo2 & 23.0 & 0.053 & 870 & 370 & 43 & 720 & 310 & 23 \\
\hline 6 & 03Cr17Mn7Ni4 & 19.8 & 0.192 & 920 & 520 & 36 & 920 & 400 & 43 \\
\hline 7 & 09Cr15Mn9NiCu2 & 17.8 & 0,068 & 970 & 510 & 37 & 820 & 430 & 21 \\
\hline 8 & 09Cr16Mn9Ni2Cu2 & 19.0 & 0.043 & 850 & 520 & 32 & - & - & - \\
\hline 9 & 02Cr16Ni10MnMo2Cu & 23.8 & 0.272 & 580 & 220 & 31 & 480 & 220 & 9 \\
\hline 10 & $06 \mathrm{Cr} 18 \mathrm{Ni} 8 \mathrm{MnCu}$ & 19.2 & 0.211 & 690 & 280 & 41 & 590 & 220 & 21 \\
\hline 11 & 07Cr16Mn8Ni4Cu2 & 18.1 & 0.076 & 760 & 430 & 35 & 730 & 340 & 41 \\
\hline 12 & 01Cr14Mn10Cu2 & 16.3 & -0.007 & - & - & - & - & - & - \\
\hline 13 & 07Cr16Mn13Mo3 & 40.0 & 1.467 & 990 & 550 & 68 & 950 & 530 & - \\
\hline 14 & 06Cr18Mn19Mo2 & 37.7 & 1.394 & 1000 & 610 & 42 & 890 & 570 & - \\
\hline 15 & 03Cr20Mn11Ni7Mo2 & 31.9 & 0.933 & - & - & - & - & - & - \\
\hline 16 & 09Cr18Ni10Ti & 18.1 & 0.177 & - & - & - & - & - & - \\
\hline
\end{tabular}

Table 3. Bending mechanical properties of steel 06Cr18Mn19Mo2.

\begin{tabular}{|c|c|c|c|c|c|c|c|c|}
\hline \multirow{3}{*}{ No. } & \multirow{3}{*}{ Processing mode } & \multicolumn{6}{|c|}{ Corrosive medium } & \multirow{3}{*}{$\begin{array}{c}\Delta R_{\mathrm{bm}} / R_{\mathrm{bm}} \\
{[\%]}\end{array}$} \\
\hline & & \multicolumn{3}{|c|}{ Air } & \multicolumn{3}{|c|}{$3.5 \%-\mathrm{NaCl}$} & \\
\hline & & $R \mathrm{~b} 0.2[\mathrm{MPa}]$ & $R_{\mathrm{bm}}[\mathrm{MPa}]$ & $A_{\mathrm{b}}[\%]$ & $R \mathrm{~b} 0.2[\mathrm{MPa}]$ & $R_{\mathrm{bm}}[\mathrm{MPa}]$ & $A_{\mathrm{b}}[\%]$ & \\
\hline 1 & Quenching from $1150^{\circ} \mathrm{C}$ (IT) & 1030 & 2040 & 42 & 960 & 1750 & 44 & 15 \\
\hline 2 & $\mathrm{IT}+$ Aging $\left(500^{\circ} \mathrm{C}, 2 \mathrm{~h}\right)$ & 1030 & 2130 & 44 & 940 & 1840 & 49 & 14 \\
\hline 3 & IT + ECAP (1.8) & - & - & - & 4400 & 6100 & 13 & - \\
\hline 4 & IT + ECAP (3.6) & 3060 & 5220 & 8 & - & - & - & - \\
\hline 5 & IT + ECAP (7.2) & - & - & - & 3800 & 5970 & 9 & - \\
\hline
\end{tabular}

From the graphs, it follows that the positive effect of molybdenum on $E_{\mathrm{b}}$ begins when the content is higher than $\sim 1.7 \%$; manganese has a dual effect: up to $\sim 9 \%$, it is negative, and above - positive; nitrogen also affects ambiguously: from a negative factor, becoming positive at the content more than $0.4 \%$. However, the analysis of the effect of individual alloying elements on the potential $E_{\mathrm{b}}$ of the steels under study does not take into account their total contribution to this indicator. To determine the additive effect of alloying elements on $E_{\mathrm{b}}$ and to present this effect in analytical form, a multiple regression analysis of the results of electrochemical studies was performed. 

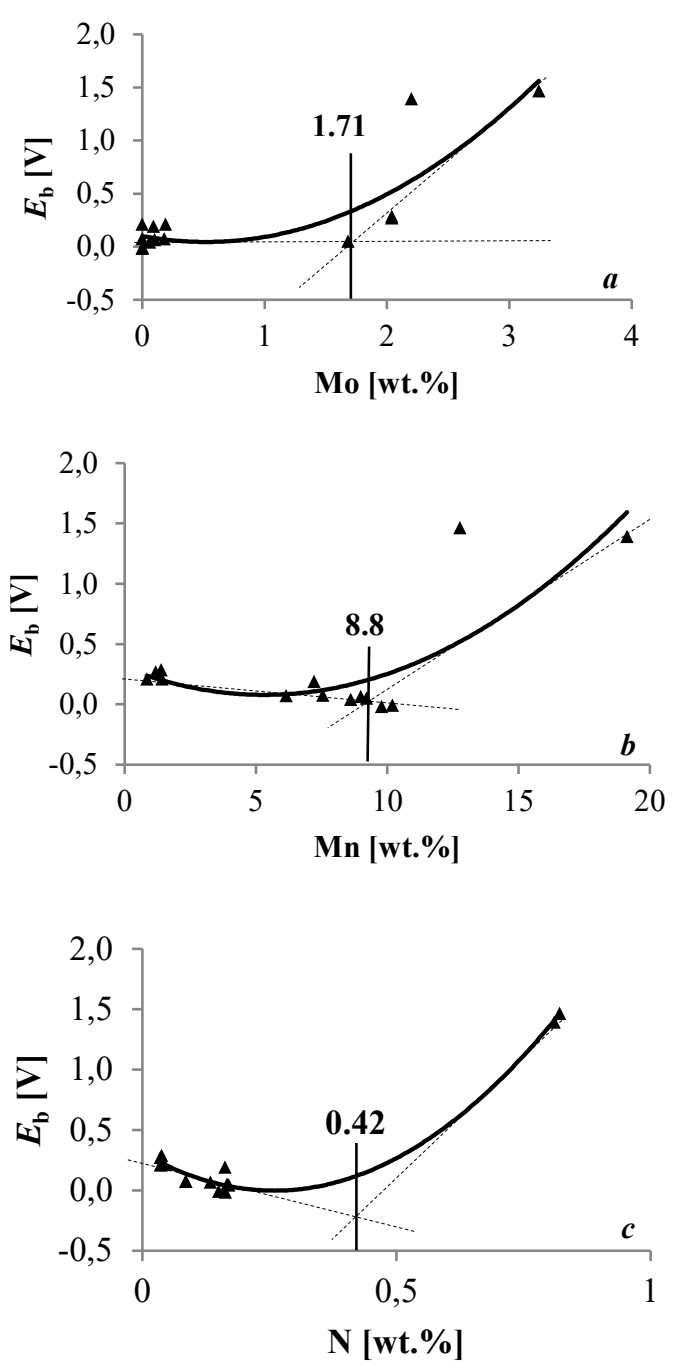

Fig. 2. The dependence of $E_{\mathrm{b}}$ on the main alloying elements content in steels: a - Mo; b - Mn; c - N.

The following equation was obtained for the dependence of the potential $E_{\mathrm{b}}$ on the chemical composition of ASS with nitrogen:

$$
\begin{aligned}
E_{b}= & -442+288 \mathrm{C}-7 \mathrm{Mn}+8 \mathrm{Cr}+50 \mathrm{Ni}+ \\
& 7 \mathrm{Mo}+2212 \mathrm{~N}+0,4 \mathrm{Cu}, \mathrm{mV},
\end{aligned}
$$

where the content of elements is expressed in wt.\%. It is natural that the most effective for improving the pitting resistance of steel are the interstitial elements. Manganese in this sample with an average content of about $6 \%$ had a negative effect.

After testing, pittings are located along the grain boundaries, as shown in fig. 3 .

The dependences of the $E_{\mathrm{b}}$ potential on the total content of interstitial atoms $(\mathrm{C}+\mathrm{N})$ and their $\mathrm{C} / \mathrm{N}$ ratios are shown in Fig. 4, from which it is clear that the curves intersect at the point $(\mathrm{C}+\mathrm{N})=\mathrm{C} / \mathrm{N}=0.5$ at a potential of $E_{\mathrm{b}}=0.2 \mathrm{~V}$, and all investigated stainless steels with low nitrogen content $(0.035-0.169 \%)$ have a lower pitting potential. Therefore, to obtain higher pitting resistance in austenitic steels $\left(E_{\mathrm{b}}>0.2 \mathrm{~V}\right)$, it is necessary that the total content $(\mathrm{C}+\mathrm{N})$ be higher than $0.5 \%$ and their ratio $\mathrm{C} / \mathrm{N}$ be less than $1 / 2$.

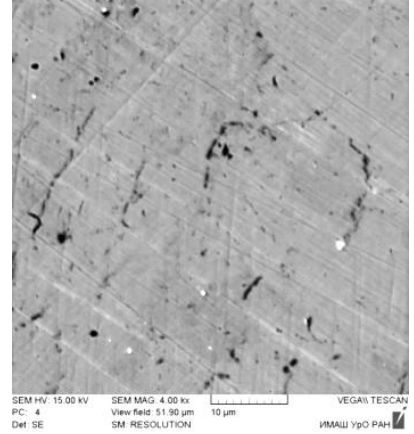

Fig. 3. Steel surface $09 \mathrm{Cr} 18 \mathrm{Ni} 10 \mathrm{Ti}$ after $\mathrm{PC}$ in $3.5 \%-\mathrm{NaCl}$.

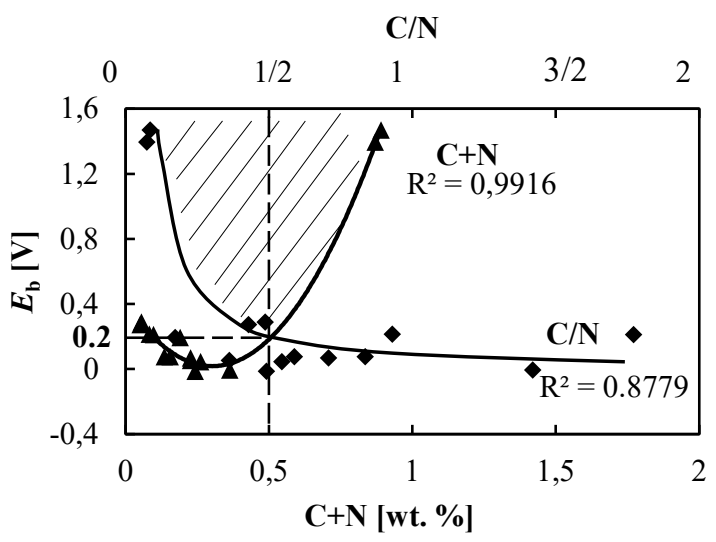

Fig. 4. The dependence of $E_{\mathrm{b}}$ on the content of $(\mathrm{C}+\mathrm{N})(\boldsymbol{\Delta})$ and $\mathrm{C} / \mathrm{N}(\diamond)$ in ASS.

The results obtained are consistent with the work [8], according to which a certain ratio of interstitial atoms with a certain total content of them characterizes optimal conditions with regard to obtaining a stable austenitic structure, without $\mathrm{M}_{2} \mathrm{~N}$ nitrides and $\mathrm{M}_{23} \mathrm{C}_{6}$ carbides. Thus, of all the steels studied in this work, having a ratio $\mathrm{C} / \mathrm{N}=1 / 2$ and a sum of $(\mathrm{C}+\mathrm{N})=0.5$, austenitic stainless steels with a nitrogen content $(0.035-0.169 \%)$ have the minimum resistance to pitting corrosion, compared to other steels with higher nitrogen content.

\subsubsection{Mechanical properties}

Mechanical tensile tests of ASS with nitrogen in air and corrosive medium of $3.5 \%-\mathrm{NaCl}$ were carried out [9]. The results of tests are shown in Table 2. Cr-Mnsteels with nitrogen $(0.130-0.170 \%)$ have higher strength and ductility, but in a corrosive medium they become more brittle than $\mathrm{Cr}-\mathrm{Ni}$-steels. The highest complex of properties was shown by $\mathrm{Cr}-\mathrm{Mn}-\mathrm{Ni}$-steel 03Cr17Mn7Ni4 (No. 6). Its strength, like the steels 02Cr16Ni10MnMo2 (No. 1) and 07Cr16Mn8Ni4Cu2 (No. 11), practically does not change, and the ductility even increases somewhat during the transition from air to corrosive medium tests. This is confirmed by the ductile dimply nature of the fracture of steel in both cases (Fig. 5). 

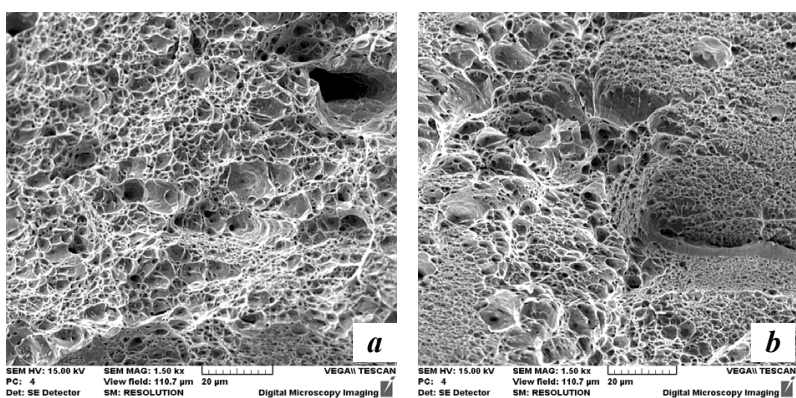

Fig. 5. Fracture surface of steel $03 \mathrm{Cr} 17 \mathrm{Mn} 7 \mathrm{Ni} 4: a-$ in air; $b$ - in $3.5 \%-\mathrm{NaCl}$.

To determine the additive effect of the alloying elements on $\sigma_{\mathrm{u}}$ and $\sigma_{\mathrm{y}}$, a multiple regression analysis of the results of mechanical tests in corrosive medium was carried out. The equations for the tensile strength $\sigma_{\mathrm{u}}$ and yield strength $\sigma_{\mathrm{y}}$ for ASS of the range studied are as follows:

$$
\begin{aligned}
\sigma_{u}= & 2157-647 C-4 M n-83 C r+8 N i- \\
& 154 M o+848 N-86 C u, M P a \\
\sigma_{y}= & 1733+1143 C+14 M n-106 C r+ \\
& 44 N i-128 M o+789 N-60 C u, M P a .
\end{aligned}
$$

The approximation of the dependences of the strength $\left(\sigma_{u}\right.$ and $\left.\sigma_{\mathrm{y}}\right)$ on $(\mathrm{C}+\mathrm{N})$ and $\mathrm{C} / \mathrm{N}$ by hyperbolas revealed the point of intersection of the curves in both case at about 0.15 with critical values of $\mathrm{N}=0.13 \%$ and $\mathrm{C}=0.02 \%$. Thus the optimal content of carbon and nitrogen in ASS should be $(\mathrm{C}+\mathrm{N}) \geq 0.15 \%$ with their ratio $\mathrm{C} / \mathrm{N} \leq 0.15$ to achieve the strength of $\sigma_{\mathrm{u}} \geq 750$ $\mathrm{MPa}$ and $\sigma_{\mathrm{y}} \geq 400 \mathrm{MPa}$.

\subsection{High nitrogen steels}

$\mathrm{PC}$ of steel $06 \mathrm{Cr} 18 \mathrm{Mn} 19 \mathrm{Mo} 2 \mathrm{~N}$ is presented in Table 4.

Table 4. Pitting corrosion of HNS.

\begin{tabular}{|c|l|c|}
\hline No. & \multicolumn{1}{|c|}{ Processing mode } & $E_{\mathrm{b}}[\mathrm{V}]$ \\
\hline 1 & $\mathrm{Q} 950^{\circ} \mathrm{C}$ & 0.263 \\
\hline 2 & $\mathrm{Q} 1000^{\circ} \mathrm{C}$ & 0.472 \\
\hline 3 & $\mathrm{Q} 1050^{\circ} \mathrm{C}$ & 1.379 \\
\hline 4 & $\mathrm{Q} 1100^{\circ} \mathrm{C}$ & 1.383 \\
\hline 5 & $\mathrm{Q} 1150^{\circ} \mathrm{C}$ & 1.394 \\
\hline 6 & $\mathrm{Q} 1150^{\circ} \mathrm{C}+\mathrm{A} 300^{\circ} \mathrm{C}(2 \mathrm{~h})$ & 1.407 \\
\hline 7 & $\mathrm{Q} 1150^{\circ} \mathrm{C}+\mathrm{A} 500^{\circ} \mathrm{C}(2 \mathrm{~h})$ & 1.390 \\
\hline 8 & $\mathrm{Q} 1150^{\circ} \mathrm{C}+\mathrm{A} 800^{\circ} \mathrm{C}(8 \mathrm{~h})$ & -0.009 \\
\hline 9 & $\mathrm{Q} 1200^{\circ} \mathrm{C}$ & -0.038 \\
\hline 10 & $\mathrm{Q} 1150^{\circ} \mathrm{C}+\mathrm{ECAP}(1,8)$ & 1.221 \\
\hline 11 & $\mathrm{Q} 1150^{\circ} \mathrm{C}+\operatorname{ECAP}(3,6)$ & 1.122 \\
\hline 12 & $\mathrm{Q} 1150^{\circ} \mathrm{C}+\operatorname{ECAP}(7,2)$ & 0.930 \\
\hline
\end{tabular}

The greatest resistance to the PC the steel has after quenching from $1050-1150{ }^{\circ} \mathrm{C}$. Aging at 300 and $500{ }^{\circ} \mathrm{C}$ after quenching from the investigated temperatures does not affect the electrochemical characteristics.

The mechanical properties of the steel, tested according to pure bending scheme are given in
Table. 3. Despite the very high strength and low ductility, the steel, after ECAP, broke by a quasicleavage without signs of brittle fracture.

The structural states in which the steel was tested were described in detail earlier in works $[10,11]$.

\section{Conclusions}

1. In the study of 14 grades of industrial ASS with nitrogen $(0.035-0.820 \%)$ and low sulfur and phosphorus contents $( \pm 0.004 \%)$, the optimum contents of interstitial atoms were established to increase the resistance of steels to PC. It was shown that, in order to increase the corrosion properties, it is advisable to coalloy the steel with carbon and nitrogen with their $\mathrm{C} / \mathrm{N}$ $<1 / 2$ ratio and the total content $(\mathrm{C}+\mathrm{N})>0.5$. In addition, in the absence of nickel, the following alloying requirements must be met for this: $\mathrm{Mn}>9 \%$, Mo $>1.7 \%$.

2. To achieve the strength of ASS with nitrogen: $\sigma_{\mathrm{B}}$ $\geq 750 \mathrm{MPa}$ and $\sigma_{0.2} \geq 400 \mathrm{MPa}$ when used in seawater, the optimum values of carbon and nitrogen in them should be $(\mathrm{C}+\mathrm{N}) \geq 0.15 \%$ when they are the ratio $\mathrm{C} / \mathrm{N}$ $\leq 0.15$.

3. The strength of HNS after SPD is increased by about 3 times, while the fracture has not brittle but quasi-cleavage mechanism and potential $E_{\mathrm{b}}$ remained higher than that of steel $09 \mathrm{Cr} 18 \mathrm{Ni10Ti}$.

\section{References}

1. M. Pujar, U. Mudali, S. Sudhansu, Corros. Sci. 53, 4178 (2011)

2. U. Mudali, High Nitrogen Steels, MISiS, Moscow, 271 (2009)

3. U. Mudali, Corros Sci. 44, 2183 (2002)

4. W. Xinqiang, High Nitrogen Steels, MISiS, Moscow, 294 (2009)

5. Y. Heon, Electrochimica Acta. 52, 2175 (2007)

6. M. Wang, High Nitrogen Steels, MISiS, Moscow, 281 (2009)

7. V. Gavriljuk, H. Berns, High Nitrogen Steels: structure, properties, manufacture, applications, Springer (1999)

8. H. Berns, V. Gavriljuk, S. Reidner, High interstitial stainless austenitic steels, Berlin, Springer (2013)

9. A. Ananyin, V. Berezovskaya Micromechanisms of plasticity, fracture and accompanied phenomena, 21, 862 (2016)

10. V. Berezovskaya, E. Merkushkin, Y. Raskovalova, Solid State Phenomena, 284, 447 (2018)

11. V. Berezovskaya, Y. Raskovalova, E. Merkushkin, R. Valiev, Metal Science and Heat Treatment, 57, 656 (2016) 